\title{
Fabrication and Magnetic Properties of A New Fe-based Amorphous Compound Powder Cores
}

\author{
Wang Xiangyue $^{1,2 *}$, Guo Feng ${ }^{2}$, Lu Caowei ${ }^{1,2}$, Lu Zhichao ${ }^{1,2}$, Li Deren ${ }^{1,2}$, and Zhou Shaoxiong ${ }^{1,2}$ \\ ${ }^{1}$ Central Iron and Steel Research Institute, Beijing 100081, China \\ ${ }^{2}$ Center of Advanced Technology and Materials Co, Ltd., Beijing 100081, China
}

(Received 2 August 2011, Received in final form 7 September 2011, Accepted 9 September 2011)

\begin{abstract}
A new Fe-based amorphous compound powder was prepared from Fe-Si-B amorphous powder by crushing amorphous ribbons as the first magnetic component and Fe-Cr-Mo metallic glassy powder by water atomization as the second magnetic component. Subsequently by adding organic and inorganic binders to the compound powder and cold pressing, the new Fe-based amorphous compound powder cores were fabricated. This new Fe-based amorphous compound powder cores combine the superior DC-Bias properties and the excellent core loss. The core loss of $500 \mathrm{~kW} / \mathrm{m}^{3}$ at $B_{m}=0.1 \mathrm{~T}$ and $f=100 \mathrm{kHz}$ was obtained When the mass ratio of $\mathrm{FeSiB} /$ FeCrMo equals 3:2, and meanwhile the DC-bias properties of the new Fe-based amorphous compound powder cores just decreased by $\mathbf{1 0 \%}$ compared with that of the $\mathrm{FeSiB}$ powder cores. In addition, with the increasing of the content of the FeCrMo metallic glassy powder, the core loss tends to decrease.
\end{abstract}

Keywords : amorphous compound powder cores, DC-bias properties, low core loss

\section{Introduction}

Recently, the soft magnetic materials of powder cores with high $B_{s}$ and low core loss attract more and more attention to be capable of dealing satisfactorily with the high-current supply and to improve the power loss characteristic [1,2]. Because of good soft magnetic properties, a large number of studies on the amorphous alloys in Febased system were reported [3-7]. Especially, Fe-Si-B amorphous powder cores [8] exhibit an excellent directcurrent overlapping characteristic at a flow of large current with a "percent permeability" of about $70 \%$ at $H=100$ Oe $(\mu=60)$ which is comparing to "High Flux" powder cores. While Fe-Cr-Mo metallic glassy powder cores [9] exhibit ultra low core loss of $329 \mathrm{~kW} / \mathrm{m}^{3}$ at $B_{m}=0.1 \mathrm{~T}$ and $f=100 \mathrm{kHz}$ which is the lowest compared to any other metallic powder cores, so compounding these alloy powder is a hopeful concept for powder cores to achieve both superior DC-Bias properties and the ultra-low core loss.

\section{Experimental Details}

Fe-Si-B amorphous powder was prepared by crushing

*Corresponding author: Tel: +86-10-58742807

Fax:+86-10-58742817, e-mail: wangxiangyue1986@163.com
$\mathrm{Fe}_{78} \mathrm{Si}_{9} \mathrm{~B}_{13}$ amorphous ribbons as the first magnetic powder, and $\mathrm{Fe}-\mathrm{Cr}$-Mo metallic glassy powder with a nominal composition of $\mathrm{Fe}_{74} \mathrm{Cr}_{2} \mathrm{Mo}_{2} \mathrm{Sn}_{2} \mathrm{P}_{10} \mathrm{Si}_{4} \mathrm{~B}_{4} \mathrm{C}_{2}$ [9] was fabricated by high pressure water atomization as the second magnetic powder. The sieved $\mathrm{FeSiB}$ amorphous powders with particle sizes $50-150 \mu \mathrm{m}$ and $\mathrm{FeCrMo}$ metallic glassy powders with particle sizes $30-45 \mu \mathrm{m}$ were used to prepare the compound powder cores.

The amorphous compound powders were uniformly mixed with $0.5 \mathrm{wt} . \%$ of organic binders (methyl silicone), $2 \mathrm{wt} . \%$ inorganic binders (a glass with low-melting point) and $0.5 \mathrm{wt} . \%$ of zinc stearate. The mixture was dried with the help of xylene as a co-solvent. By cold pressing at $2 \mathrm{GPa}$, and then being annealed at $693 \mathrm{~K}$ for $30 \mathrm{~min}$ in vacuum, the $\mathrm{FeSiB}$ amorphous powder cores, $\mathrm{FeCrMo}$ metallic glassy powder cores and the new Fe-based amorphous compound powder cores were fabricated. The core size was $22.9 \phi \times 14.1 \phi \times 6.5 \mathrm{~mm}$.

The phase structures, crystallization behavior and magnetic properties of the powders were examined by XRD and VSM, respectively. Examination of morphology was carried out using SEM. Initial permeability was calculated from core inductance measured by Agilent 4294A Impedance Analyser, the DC bias field performance was measured by Agilent $4980 \mathrm{~A}$ and the magnetic core loss was measured by IWATSU SY-8232 B-H analyzer. 


\section{Results and Discussion}

Fig. 1 and Fig. 2 show morphology of the FeSiB crushed amorphous powders and FeCrMo water-atomized metallic glassy powders observed by SEM. High pressure water-atomized powders exhibit a clean and smooth surface and spherical shape. In contrast, crushed powders have irregular shapes and rougher surface morphologies. The particle sizes of FeSiB crushed amorphous powders and FeCrMo water-atomized metallic glassy powders were 50$150 \mu \mathrm{m}$ and $30-45 \mathrm{~mm}$ respectively, which was suitable for forming consolidated powder cores with high density. The amorphous state of FeCrMo powders and most of FeSiB powders was confirmed by X-ray diffraction patterns from Fig. 3.

The further magnetic properties of powders used in pressing were shown in Table 1. Both of the FeSiB and FeCrMo powders all have relative high flux density of 1.5T [8] and 1.06T [9], respectively.

Fig. 4 shows that the dependence of the core loss Pcv

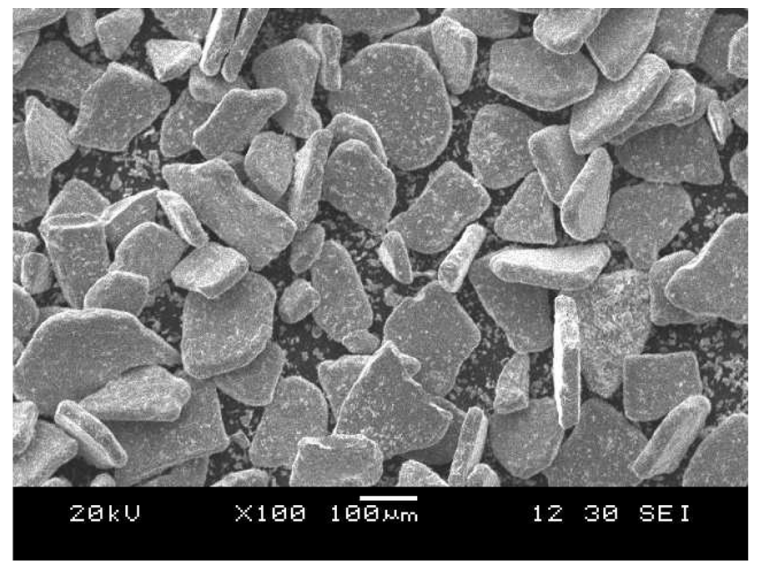

Fig. 1. Morphology of FeSiB crushed amorphous powders.

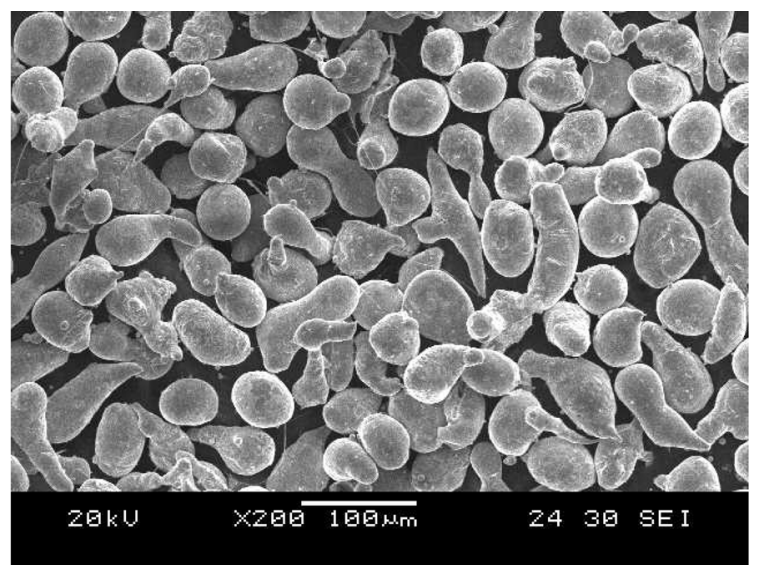

Fig. 2. Morphology of FeCrMo metallic glassy powders by high pressure water atomization.

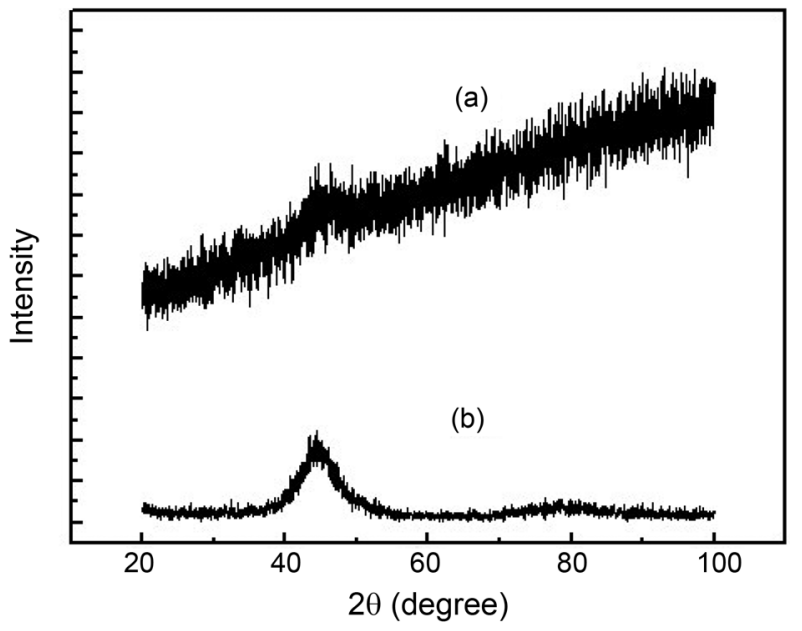

Fig. 3. XRD patterns of $\mathrm{FeSiB}$ and FeCrMo powders. (a) FeSiB powders. (b) FeCrMo powders.

Table 1. Saturated flux density of the FeSiB and FeCrMo powders

\begin{tabular}{ccc}
\hline \hline Composition & Particle size & $\mathrm{B}_{\mathrm{s}}$ \\
\hline FeSiB & $50-150 \mu \mathrm{m}$ & $1.5 \mathrm{~T}$ \\
FeCrMo & $30-45 \mu \mathrm{m}$ & $1.06 \mathrm{~T}$ \\
\hline
\end{tabular}

of $\mathrm{FeSiB}$ powder cores on particle sizes of $\mathrm{FeSiB}$ powders at $B_{m}=0.1 \mathrm{~T}, f=100 \mathrm{kHz}$. It can be seen from the figure that the core loss of FeSiB powder cores increases greatly when the particle sizes of powders below $50 \mu \mathrm{m}$. Usually the eddy current loss is proportional to the particle size when the shape of particles is spherical. However, in this article, the FeSiB crushed powders have irregular shapes and rougher surface morphologies, so eddy current loss has not been affected largely by the particle size. The residual stress of deformation processing would be increased largely when crushing the FeSiB ribbons to powders with particle sizes below $50 \mu \mathrm{m}$, which results in the increase of hysteresis loss, while the residual stress of powders with particle sizes over $50 \mu \mathrm{m}$ is small. That may be the main reason why the core loss is inversely proportional to the particle size. It could be explained by the residual deformation processing when crushing the ribbons to powders with particle sizes below $50 \mu \mathrm{m}$. That is extremely unfavorable to the use of powder cores, so considering to use FeCrMo water-atomized powders as a substitution of $\mathrm{FeSiB}$ powders with particle size below $50 \mu \mathrm{m}$ would be a solution to this problem.

Fig. 5 shows that the dependence of the core loss $P_{c v}$ on the FeCrMo's percentage in the amorphous compound powders at $B_{m}=0.1 \mathrm{~T}, f=100 \mathrm{kHz}$. The core loss $P c v$ tends to decrease with increasing the percentage of FeCrMo metallic glassy powders in the amorphous compound 


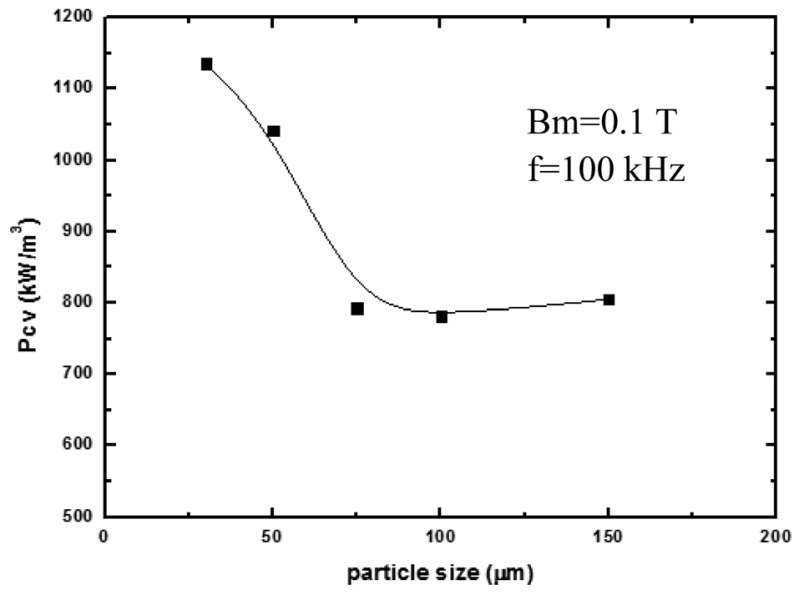

Fig. 4. The dependence of the core loss $P_{c v}$ of FeSiB powder cores on particle sizes of $\mathrm{FeSiB}$ powders at $B_{m}=0.1 \mathrm{~T}, f=100$ $\mathrm{kHz}$.

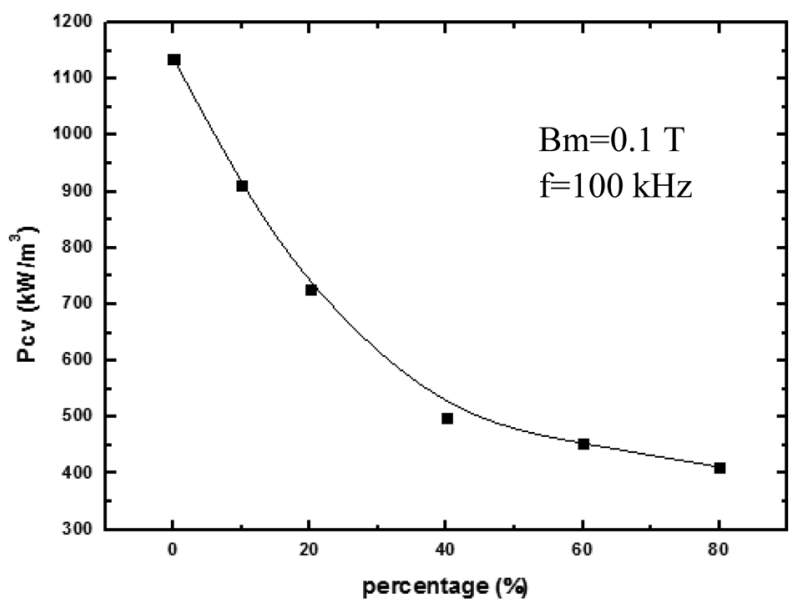

Fig. 5. Variation of $P_{c v}$ of the amorphous compound powder cores with FeCrMo's percentage in the amorphous compound powders at $B_{m}=0.1 \mathrm{~T}, f=100 \mathrm{kHz}$.

powders. For the core made of compound powders containing $60 \mathrm{wt} . \% \mathrm{FeSiB}$ crushed powders $(50-150 \mu \mathrm{m})$ and 40 wt. $\%$ FeCrMo atomized powders $(30-45 \mu \mathrm{m}), P_{c v}$ at $100 \mathrm{kHz}$ for $B_{m}=0.1 \mathrm{~T}$ was only $500 \mathrm{~kW} / \mathrm{m}^{3}$, which was a very low loss comparable to that of previously developed $\mathrm{FeSiB}$ powder cores.

Fig. 6 shows the dependence of the core loss on flux density over the frequency range of $25-100 \mathrm{kHz}$. It can be seen from the figure that the core loss versus flux density curves show good linearity in the range from 25 to 100 $\mathrm{kHz}$. This powder core was made of amorphous compound powders containing 60 wt.\% FeSiB crushed powders and 40 wt.\% FeCrMo atomized powders. The decrease in Pcv can be explained by the combination of relatively higher resistivity and lower coercivity of FeCrMo metallic glassy powders compared with that of FeSiB amorphous powders.

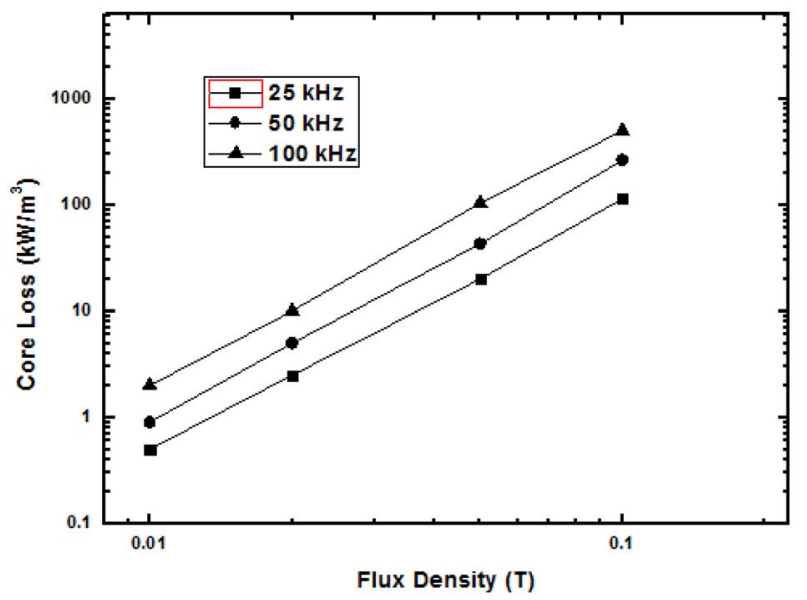

Fig. 6. The dependence of core loss $P_{c v}$ on flux density at different frequencies.

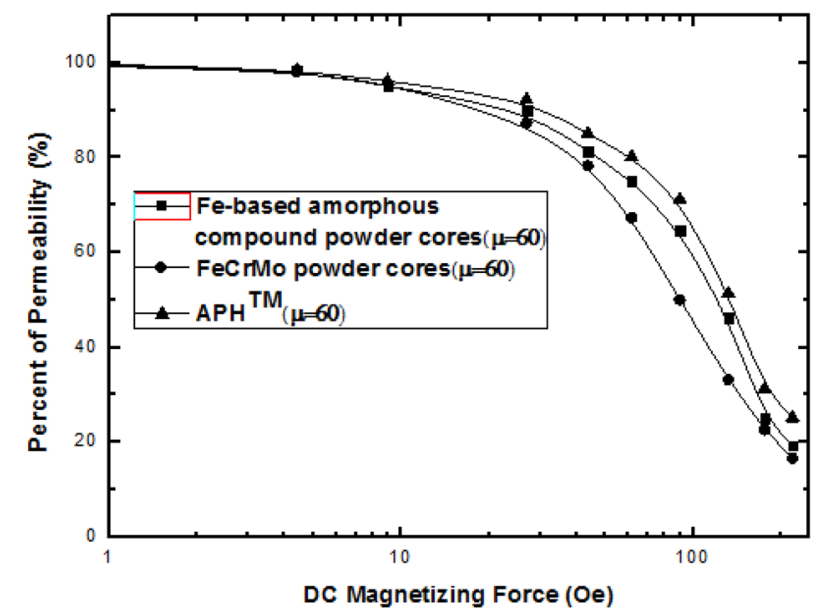

Fig. 7. (Color online) The dependence of permeability change on bias field at $100 \mathrm{kHz}$ for different kinds of magnetic powder cores.

Relatively higher resistivity results in the decrease in eddy current loss, and lower coercivity benefits the decrease in hysteresis loss.

Fig. 7 shows the dependence of percent of permeability change on the bias field at $100 \mathrm{kHz}$. The Fe-based amorphous compound powder cores (FeSiB:FeCrMo = 3:2) shows comparable permeability change performance with APHTM $(\mu=60)$ powder cores [8] over the bias field range to 100 Oe, while has significantly better performance than FeCrMo powder cores at the bias field range to 100 Oe. The improvement of percent permeability is attributed to the relatively higher $B s$ of FeSiB compared with that of FeCrMo.

\section{Conclusions}

The new Fe-based amorphous compound powder cores 
made of the compound powders containing $\mathrm{FeSiB}$ crushed amorphous powders and FeCrMo water-atomized metallic glassy powders were fabricated. This Fe-based amorphous compound powder cores exhibit superior magnetic properties. Extremely low core loss was ontained by using FeCrMo water-atomized metallic glassy powders as a substitution of $\mathrm{FeSiB}$ powders smaller than $50 \mu \mathrm{m}$. When the mass ratio of $\mathrm{FeSiB} / \mathrm{FeCrMo}$ equals $3: 2$, the core loss of $500 \mathrm{~kW} / \mathrm{m}^{3}$ at $B_{m}=0.1 \mathrm{~T}$ and $f=100 \mathrm{kHz}$ was obtained, and meanwhile the DC-bias properties of the new Fe-based amorphous compound powder cores were obviously better than FeCrMo powder cores, just decreased by $10 \%$ compared with the $\mathrm{APH}^{\mathrm{TM}}$ powder cores [8]. In addition, with the increasing of the ratio of that of the FeCrMo metallic glassy powder, the core loss tends to decrease.

The amorphous compound powder cores in this study are expected to be used for downsizing of choking coils or fly-back transformers operating at high frequency and high power range.

\section{Acknowledgment}

This wosk was supported by the National Hi-Tech
Research and Developmemt Program (Grant No. 2001AA327030) and Science and Technology. Program of Beijing (Grant No. D0405003040121).

\section{References}

[1] I. Otsuka, T. Kadomura, K. Ishiyama, and M. Yagi, IEEE Trans. Magn. 45, 4294 (2009).

[2] H. Matsumoto, A. Urata, Y. Yamada, and A. Inoue, IEEE Trans. Magn. 46, 373 (2010).

[3] I. Endo, I. Otsuka, R. Okuno, A. Shintani, M. Yoshino, and M. Yagi, IEEE Trans. Magn. 355, 3385 (1999).

[4] M. Yagi, I. Endo, I. Otsuka, H. Yamamoto, R. Okuno, H. Koshimoto, and A. Shintani, J. Magn. Magn. Mater. 215216, 284 (2000).

[5] S. Yoshida, T. Mizushima, T. Hatanai, and A. Inoue, IEEE Trans. Magn. 36, 3424 (2000).

[6] Y. Ogawa, M. Naoe, Y. Yoshizawa, and R. Hasegawa, J. Magn. Magn. Mater. 304, 675 (2006).

[7] I. Otsuka, K. Wada, Y. Maeta, T. Kadomura, and M. Yagi, IEEE Traps. Magn. 44, 3891 (2008).

[8] Amosense $\mathrm{APH}^{\mathrm{TM}},<\mathrm{http} / / / \mathrm{www} . a m o s e n s e . c o . k r />$.

[9] Zhang, L., Li, D. R., Lu, Z. C., et al., Sci China Tech. Sci. 53, 1290 (2010). 